\title{
TRATAMENTOS PRÉ-GERMINATIVOS EM SEMENTES DE Hibiscus sabdariffa L. (Malvales - Malvaceae)
}

Bruno Rafael Alves Rodrigues ${ }^{1}$; Hugo Tiago Ribeiro Amaro²; Andréia Márcia Santos de Souza

David $^{1}$; Lucas Vinícius de Souza Cangussú ${ }^{1}$; Miquéias de Oliveira Assis ${ }^{1}$; Dorismar David Alves $^{1}$

${ }^{1}$ UNIMONTES - Universidade Estadual de Montes Claros, e-mail: rafabrunoalves@ hotmail.com

${ }^{2}$ UFV - Universidade Federal de Viçosa, Departamento de Fitotecnia, e-mail: htiagoamaro@ yahoo.com.br

\section{RESUMO}

Objetivou-se com este trabalho, avaliar a eficiência de tratamentos pré-germinativos na superação da dormência de sementes de Hibiscus sabdariffa L. O delineamento experimental utilizado foi o inteiramente casualizado com quatro repetições de 50 sementes. Os tratamentos consistiram em: T1 - testemunha (sem tratamento pré-germinativo); T2 - pré-esfriamento das sementes sob temperatura de $10{ }^{\circ} \mathrm{C}$ por 4 dias; T3 - escarificação térmica com imersão das sementes em água destilada a temperatura de $70^{\circ} \mathrm{C}$ por $10 \mathrm{~min}$; e T4 - escarificação química com imersão das sementes em ácido sulfúrico a $98 \%$ por $5 \mathrm{~min}$. As sementes foram avaliadas quanto ao teor de água, a germinação e ao vigor, primeira contagem de germinação, emergência de plântulas, índice de velocidade de emergência, comprimento e massa fresca de plântulas. Os dados foram submetidos à análise de variância e as médias comparadas pelo teste Tukey a 5\% de probabilidade. Diante dos resultados obtidos conclui-se que a escarificação química com ácido sulfúrico durante 5 minutos reduz a dormência e promove incrementos na germinação e no vigor das sementes de $H$. sabdariffa.

Palavras-chave: Dormência, germinação, planta medicinal, vinagreira

\section{PRE-GERMINATION TREATMENTS IN SEEDS OF Hibiscus sabdariffa L. (Malvales - Malvaceae)}

\begin{abstract}
The objective of this study was to evaluate the efficiency of pre-germination treatments for dormancy break in seeds of Hibiscus sabdariffa $\mathrm{L}$. The experimental design was completely randomized with four replications of 50 seeds. The treatments were: T1 - control (untreated pregermination), $\mathrm{T} 2$ - precooling the seeds under temperature of $10^{\circ} \mathrm{C}$ for 4 days, $\mathrm{T} 3$ - thermal scarification soaking the seeds in distilled water at $70{ }^{\circ} \mathrm{C}$ for $10 \mathrm{~min}$ and $\mathrm{T} 4-$ water scarification chemical immersion of the seeds in $98 \%$ sulfuric acid for 5 min. Seeds were evaluated for water content, germination and vigor, first germination, seedling emergence, speed of emergence index, length and fresh weight of seedlings. Data were subjected to analysis of variance and means were compared by Tukey test at 5\% probability. Based on these results it is concluded that the chemical scarification with sulfuric acid for 5 min reduces numbness and promotes increases in germination and vigor of seeds of $H$. sabdariffa.
\end{abstract}

Keywords: Dormancy, germination, medicinal plant, vinegar 


\section{INTRODUÇÃO}

A vinagreira (Hibiscus sabdariffa L.) também conhecida como rosela, azedinha, quiabo azedo, dentre outros é uma das espécies consideradas como subutilizadas no Brasil, porém com grande potencial para fazer parte da cadeia produtiva das hortaliças em nível local, regional ou nacional (MELO, 2007). Apresenta-se como um arbusto anual vigoroso, ereto ou ramificado conforme a condução, podendo chegar aos 3 metros de altura (BRASIL, 2010).

É usada como hortaliça, medicinal e ornamental, sendo rica em vitamina A e B1 e em ácidos: cítrico, málico e tartárico. Indicado como diurético, calmante, estomáquico é ainda usado na fabricação de doces, geleias e sucos, sendo os cálices a parte mais consumida da planta (CASTRO et al., 2004).

O estudo da germinação das sementes de espécies medicinais tem merecido atenção especial da comunidade científica, devido ao incremento ao seu potencial farmacológico, aliado a necessidade de proceder a cultivos racionais destinados a produção de fitoterápicos (PEREIRA, 1992).

Outro fator de relevância no estudo da germinação é a dormência das sementes, fator caracterizado pelo atraso na germinação quando, mesmo as sementes encontrando as condições favoráveis, não germinam. O fenômeno de dormência em sementes, que geralmente ocorre após atingirem a maturidade fisiológica, advêm da adaptação da espécie as condições ambientais em que ela se reproduz, sendo, portanto, um recurso utilizado pelas plantas para germinarem na estação mais propícia ao seu desenvolvimento, buscando por meio disso a perpetuação da espécie (GUIMARÃES et al., 2006).

Considerando a adaptação das espécies aos seus hábitats, a dormência é benéfica na medida em que impede a germinação das sementes até que se instalem condições ambientais propícias, impede a viviparidade e atua na conservação in situ, permanecendo viáveis no solo por décadas, reduzindo a probabilidade de extinção. Entretanto, espécies que apresentam esse mecanismo exigem tratamentos especiais para a quebra da dormência o que representa aumentos no custo de produção (GUIMARÃES et al., 2006). A dormência em sementes de plantas cultivadas é atribuída usualmente a tegumentos impermeáveis e à imaturidade fisiológica.

Ao se deparar com esse fenômeno, há necessidade de conhecer como as espécies superam o estado de dormência em condições naturais, a fim de que, por analogia, sejam desenvolvidos tratamentos alternativos para germinação rápida e uniforme, na utilização agronômica da espécie. Diversos métodos têm sido empregados visando a superação da dormência, principalmente quando se refere ao impedimento da entrada de água, tais como: a escarificação mecânica e química, a embebição das sementes em água e tratamentos com altas temperaturas. Contudo, a aplicação e eficiência desses tratamentos dependem do grau de dormência, que é variável entre diferentes espécies, procedências e anos de coleta (OLIVEIRA et al., 2003).

Objetivou-se com este trabalho avaliar a eficiência de diferentes tratamentos pré-germinativos na superação da dormência de sementes de $H$. sabdariffa $\mathrm{L}$.

\section{MATERIAL E MÉTODOS}

O experimento foi realizado no Laboratório de Análise de Sementes, do Departamento de Ciências Agrárias da Universidade Estadual de Montes Claros (DCA/UNIMONTES), no município de Janaúba, norte de Minas Gerais, no período de março a abril de 2012, com as seguintes coordenadas geográficas: $15^{\circ} 47^{\prime} 50^{\prime}$ ' latitude Sul e $43^{\circ} 18^{\prime} 31^{\prime \prime}$ longitude Oeste, e altitude 
de $516 \mathrm{~m}$. O clima da região segundo classificação de Koppen é do tipo "AW" (tropical com inverno seco), com temperatura e precipitação média anual de $25^{\circ} \mathrm{C}$ e $900 \mathrm{~mm}$, respectivamente.

Foram utilizadas sementes de $H$. sabdariffa L. extraídas manualmente de frutos maduros coletados no Horto de Plantas Medicinais - HPM da UNIMONTES, Janaúba - MG. Após a extração, as sementes foram acondicionadas em sacos de papel e armazenadas por trinta dias em condições ambientais de laboratório sob temperatura média de $25^{\circ} \mathrm{C}$ e umidade relativa do ar de $65 \%$.

$\mathrm{O}$ delineamento experimental utilizado foi inteiramente casualizado (DIC) com quatro repetições. Os tratamentos consistiram em: $\mathrm{T}_{1^{-}}$sementes que não receberam nenhum tipo de tratamento prégerminativo para superação de dormência; $\mathrm{T}_{2}$ - pré-esfriamento das sementes em câmara tipo BOD a $10{ }^{\circ} \mathrm{C}$ por 4 dias; $\mathrm{T}_{3-}$ escarificação térmica com imersão das sementes em água destilada à temperatura de $70{ }^{\circ} \mathrm{C}$ por $10 \mathrm{~min}$, onde permaneceram até o completo resfriamento da mesma. $\mathrm{T}_{4}-$ escarificação química com imersão das sementes em ácido sulfúrico $\left(\mathrm{H}_{2} \mathrm{SO}_{4}\right)$ a $98 \%$ por 5 min. $\mathrm{Na}$ imersão em $\mathrm{H}_{2} \mathrm{SO}_{4}$ as sementes foram colocadas em Becker e constantemente revolvidas com um bastão de vidro durante $5 \mathrm{~min}$, objetivando uniformizar a sua ação abrasiva. Decorrido o período pré-estabelecido, as sementes foram lavadas em água corrente por 10 min para a retirada de resíduos do ácido.

Foram realizadas as seguintes determinações para avaliação da qualidade fisiológica das sementes: Teor de água: determinado conforme metodologia prescrita nas Regras para Análise de Sementes - RAS (BRASIL, 2009), utilizando o método da estufa, a $105 \pm 3{ }^{\circ} \mathrm{C}$, durante $24 \mathrm{~h}$, com três repetições de $5 \mathrm{~g}$ de sementes, sendo os resultados expressos em $\%$.
Teste de Germinação: foram utilizadas quatro repetições de 50 sementes por tratamento, distribuídas uniformemente sobre germitest na forma de rolo, umedecidos com água destilada, na proporção de 2,5 vezes o seu peso seco. Os rolos foram colocados em germinador previamente regulado à temperatura constante de $25{ }^{\circ} \mathrm{C}$. Os resultados foram expressos em porcentagem de plântulas normais computadas após determinação, em testes preliminares, dos dias para a primeira e última contagem do teste $\left(7\right.$ e $14^{\circ}$, respectivamente), conforme as RAS (BRASIL, 2009), onde foram avaliadas também a porcentagem de plântulas anormais, sementes mortas e sementes dormentes.

Primeira contagem de germinação: Os resultados do teste de primeira contagem foram obtidos pelo número de plântulas normais, determinado por ocasião da primeira contagem do teste de germinação, ao sétimo dia após a semeadura (BRASIL, 2009).

Emergência de plântulas: realizado sob condições ambientais de casa de vegetação e a semeadura foi a uma profundidade de dois centímetros em bandejas plásticas, contendo como substrato areia lavada e esterilizada, umedecida com quantidade de água equivalente a $60 \%$ da capacidade de retenção, cuja umidade foi mantida por meio de regas diárias (BRASIL, 2009). Foram utilizadas quatro repetições de 50 sementes por tratamento e os resultados expressos em porcentagem de plântulas normais emergidas, que apresentaram alça cotiledonar visível, até a estabilização do estande, aos quatorze dias.

Índice de velocidade de emergência: conduzido em conjunto com o teste de emergência de plântulas, anotando-se diariamente, no mesmo horário, o número de plântulas normais emergidas até a estabilização da emergência. Ao final do teste, com os dados diários do número de 
plântulas emergidas, foi calculado o índice de velocidade de emergência, empregandose a fórmula proposta por Maguire (1962).

Comprimento de plântulas: no final do teste de emergência foi determinado, com o auxílio de uma régua milimetrada, o comprimento médio das plântulas consideradas normais, sendo os resultados expressos em centímetros $(\mathrm{cm})$.

Massa fresca de plântulas: As plântulas normais obtidas no teste de emergência foram previamente pesadas, colocadas em sacos de papel e levadas para secar em estufa com circulação forçada de ar, a $65{ }^{\circ} \mathrm{C}$ constante, durante 72 h. Após este período, as amostras foram colocadas para resfriar em dessecadores e pesadas em balança de precisão, sendo os resultados expressos em gramas (g).

Os dados foram submetidos à análise de variância utilizando-se o programa estatístico SISVAR® (FERREIRA, 2008) e para a comparação das médias utilizou-se o teste de Tukey, em nível de $5 \%$ de probabilidade.

\section{RESULTADOS E DISCUSSÃO}

A determinação do teor de água das sementes de vinagreira, como procedimento inicial na realização da pesquisa, indicou que as sementes apresentaram-se com 9,6\% de umidade. Este valor está dentro do padrão considerado ideal para a colheita e armazenamento de sementes de espécies consideradas ortodoxas, como é o caso da vinagreira. Segundo Kermode (1997), sementes ortodoxas são aquelas, que ao final do processo de desenvolvimento e maturação, sofrem secagem natural na planta mãe, finalizando o desenvolvimento com baixo conteúdo de água, em torno de 5 a $10 \%$ da matéria fresca. Adicionalmente, o teor de água inicial das sementes é um fator primordial para padronização dos testes de avaliação de qualidade a serem realizados e, consequentemente, para a obtenção de resultados consistentes (COIMBRA et al., 2007).

Os resultados de germinação (GE), plântulas anormais (PA) e sementes dormentes (SD) foram influenciados $(\mathrm{P}<0,05)$ pelos tratamentos pré-germinativos empregados na superação da dormência de sementes de $H$. sabdariffa L. (Tabela 1). Para a variável, sementes mortas (SM) não foi verificado efeito $(\mathrm{P}>0,05)$ dos tratamentos aplicados.

O pré-resfriamento a $10^{\circ} \mathrm{C}$ por 4 dias não foi eficiente em promover incrementos na porcentagem de germinação das sementes (Tabela 1), sendo os resultados estatisticamente semelhantes aos obtidos na testemunha (sem tratamento prégerminativo). No entanto, verificou-se que ao se utilizar o ácido sulfúrico concentrado por 5 min como tratamento pré-germinativo nas sementes de $H$. sabdariffa L., houve incrementos significativos na porcentagem de germinação em relação à testemunha e demais tratamentos.

Concordando com o presente estudo, Martins et al. (2011) verificaram que a imersão das sementes em ácido sulfúrico durante 4 min mostrou-se eficiente na superação de dormência presente nas sementes de Abelmoschus esculentus (L.) Moench, pertencente à mesma família de $H$. sabdariffa $\mathrm{L}$.

Vale salientar que o tratamento com ácido sulfúrico tem sido indicado por vários autores como um dos mais promissores para superação da dormência em sementes de diversas espécies (ALVES et al., 2006; DUTRA et al., 2007; MARTINS \& NAKAGAWA, 2008; SILVA et al., 2009; ARANHO \& PAIVA, 2012; OLIVEIRA et al., 2012). 
Tabela 1. Resultados médios de germinação (GE), plântulas anormais (PA), sementes mortas (SM) e sementes dormentes (SD) de $H$. sabdariffa L. submetidas a tratamentos prégerminativos.

\begin{tabular}{lcccc}
\hline \multirow{2}{*}{ Tratamentos } & \multicolumn{4}{c}{ Variáveis } \\
\cline { 2 - 5 } & \% GE & n'PA & \%SM & \%SD \\
\hline 1 - Testemunha & $33 \mathrm{~B}$ & $6 \mathrm{~A}$ & 28 & $33 \mathrm{~B}$ \\
2 - Pré-esfriamento a $10{ }^{\circ} \mathrm{C} / 4$ dias & $31 \mathrm{~B}$ & $8 \mathrm{~A}$ & 24 & $37 \mathrm{~B}$ \\
3 - Água quente a $70{ }^{\circ} \mathrm{C} / 10 \mathrm{~min}$ & $0 \mathrm{C}$ & $2 \mathrm{~B}$ & 20 & $78 \mathrm{~A}$ \\
4 - Escarificação química $\mathrm{H}_{2} \mathrm{SO}_{4} / 5$ min & $46 \mathrm{~A}$ & $1 \mathrm{~B}$ & 23 & $30 \mathrm{~B}$ \\
\hline Médias & 27,5 & 4,2 & 23,7 & 44,5 \\
\hline C.V $(\%)$ & 17,37 & 67,12 & 25,30 & 16,46 \\
\hline
\end{tabular}

Em cada coluna, médias seguidas pela mesma letra não diferem entre si pelo teste de Tukey a 5\% de probabilidade.

A superação da dormência com ação do ácido sulfúrico se dá pelo amolecimento do tegumento das sementes, resultante da remoção da cutícula e exposição das camadas de macroesclereídes, permitindo, assim permeabilidade mais homogênea (SANTARÉM \& ÁQUILA, 1995). No entanto, deve-se ressaltar que tanto a concentração quanto o tempo de exposição das sementes são fatores que, se não forem bem elucidados para a cultura em estudo, podem danificar o embrião e prejudicar os resultados obtidos.

Nota-se que as sementes escarificadas termicamente (água $70{ }^{\circ} \mathrm{C}$ por 10min), apresentaram germinação nula, (Tabela 1). Possivelmente, a imersão das sementes em água quente provocou danos aos embriões, comprometendo a viabilidade das mesmas. Os resultados obtidos no presente trabalho discordam dos encontrados por Amaro et al. (2012) que obtiveram resultados satisfatórios ao utilizar o tratamento térmico $\left(70^{\circ} \mathrm{C}\right.$ por $\left.5 \mathrm{~min}\right)$ na superação de dormência de sementes de manjericão (Ocimum basilicum L.). Brito et al. (2006) também constataram que a água quente sob diferentes temperaturas foi eficiente na germinação das sementes de Ocimum canum Sims, reduzindo a porcentagem de sementes dormentes.
A porcentagem de plântulas anormais provenientes das sementes escarificadas quimicamente $\left(\mathrm{H}_{2} \mathrm{SO}_{4}\right.$ por $\left.5 \mathrm{~min}\right)$, e as que receberam pré-esfriamento a $10{ }^{\circ} \mathrm{C}$ por 4 dias foi estatisticamente inferior aos resultados obtidos nos demais tratamentos (água a 70 ${ }^{\circ} \mathrm{C}$ por 10 min e testemunha).

Durante as avaliações, as sementes mortas de vinagreira foram classificadas como aquelas que no final do teste de germinação não germinaram, apresentandose deterioradas e atacadas por microrganismos.

Observando a porcentagem de sementes dormentes (Tabela 1), verifica-se que as sementes imersas em água destilada a $70{ }^{\circ} \mathrm{C}$ por $10 \mathrm{~min}$ apresentaram resultados superiores em comparação aos demais tratamentos pré-germinativos, garantindo dessa forma, menores respostas fisiológicas das sementes. Esses resultados corroboram com os obtidos por Scalon et al. (2008), os quais verificaram que o tratamento com choque térmico não permitiu a germinação das sementes de cipó-São-João [Pyrostegia venusta (Ker Gawl.) Miers] em nenhuma das temperaturas de incubação estudadas.

Pôde-se verificar que os menores valores obtidos nas porcentagens de sementes dormentes foram provenientes dos tratamentos 2 e 4, que não diferiram da testemunha. 
Tabela 2. Resultados médios de primeira contagem (PC), emergência de plântulas (EP), índice de velocidade de emergência (IVE), comprimento de plântulas (CP) e matéria seca (MS) de plântulas de H. sabdariffa L., submetidas a diferentes tratamentos prégerminativos.

\begin{tabular}{lrcccc}
\hline \multirow{2}{*}{ Tratamentos } & \multicolumn{5}{c}{ Variáveis } \\
\cline { 2 - 6 } & PC $(\%)$ & EP $(\%)$ & IVE & CP $(\mathbf{c m})$ & MS $(\mathbf{g})$ \\
\hline 1 - Testemunha & $13 \mathrm{C}$ & $27 \mathrm{~B}$ & $1,5 \mathrm{~B}$ & $7,7 \mathrm{~B}$ & $1,7 \mathrm{~B}$ \\
2 - Pré-esfriamento a $10{ }^{\circ} \mathrm{C} / 4$ dias & $24 \mathrm{~B}$ & $44 \mathrm{~A}$ & $3,3 \mathrm{~A}$ & $8,8 \mathrm{~B}$ & $3,3 \mathrm{~A}$ \\
3 - Água quente a $70{ }^{\circ} \mathrm{C} / 10 \mathrm{~min}$ & $0 \mathrm{D}$ & $2 \mathrm{C}$ & $0,1 \mathrm{C}$ & $3 \mathrm{C}$ & $0,0 \mathrm{C}$ \\
4 - Escarificação química $\mathrm{H}_{2} \mathrm{SO}_{4} / 5 \mathrm{~min}$ & $37 \mathrm{~A}$ & $54 \mathrm{~A}$ & $4,5 \mathrm{~A}$ & $10,7 \mathrm{~A}$ & $4,3 \mathrm{~A}$ \\
\hline Médias & 18,5 & 31,8 & 2,6 & 7,5 & 2,3 \\
\hline C.V $(\%)$ & 26,70 & 18,87 & 26,93 & 6,81 & 25,73 \\
\hline
\end{tabular}

Em cada coluna, médias seguidas pela mesma letra não diferem entre si pelo teste de Tukey a $5 \%$ de probabilidade.

Foram registrados (Tabela 2) os resultados médios de primeira contagem (PC), emergência de plântulas (EP), índice de velocidade de emergência (IVE), comprimento de plântulas (CP) e massa seca (MS) de plântulas de $H$. sabdariffa L., em função dos tratamentos pré-germinativos. Verifica-se que houve efeito dos tratamentos empregados para todas as variáveis analisadas.

Ao se avaliar o vigor das sementes pelo teste de primeira contagem de germinação, observa-se que houve aumento significativo na velocidade de germinação das sementes ao se utilizar o ácido sulfúrico por 5 min como tratamento pré-germinativo (Tabela 2), confirmando os resultados superiores de germinação apresentados anteriormente (Tabela 1). Os resultados da primeira contagem do teste de germinação indicam que as amostras que apresentaram maiores porcentagens de plântulas normais, na primeira avaliação estabelecida pelas RAS (BRASIL, 2009), são as mais vigorosas, por apresentarem maior velocidade no processo.

A porcentagem de emergência de plântulas (EP) foi baixa no tratamento imersão em água quente $\left(70{ }^{\circ} \mathrm{C}\right.$ por $\left.10 \mathrm{~min}\right)$ seguido da testemunha, enquanto que os melhores tratamentos para a superação da dormência de sementes de $H$. sabdariffa L. foram a escarificação química $\left(\mathrm{H}_{2} \mathrm{SO}_{4}\right.$ por 5 min) e pré-resfriamento a $10^{\circ} \mathrm{C}$ por 4 dias (Tabela 2).

Considerando-se todos os tratamentos estudados, valores mais expressivos no índice de velocidade de emergência (IVE) foram verificados nas sementes tratadas com ácido sulfúrico (Tabela 2). Maiores índices indicam que as sementes germinaram mais rapidamente e de forma homogênea, sendo, portanto, mais vigorosas. Esses resultados foram similares aos encontrados nas variáveis comprimento e matéria seca de plântulas (Tabela 2).

De maneira semelhante ao teste de germinação, verificou-se que as sementes imersas em água quente a $70{ }^{\circ} \mathrm{C}$ por $5 \mathrm{~min}$ apresentaram valores estatisticamente inferiores nos resultados de vigor em todas as variáveis analisadas (Tabela 2) ressaltando que, possivelmente, a alta temperatura da água prejudicou os processos fisiológicos iniciais da germinação, conforme comentado anteriormente. Esses resultados discordam dos obtidos por Martins et al. (2011) que verificaram efeito positivo do tratamento térmico na cultura do quiabo, justificando que as altas temperaturas foram mais eficientes em 
acelerar o processo germinativo das sementes.

Os testes de vigor são importantes, uma vez que permitem avaliar o potencial fisiológico das sementes o que garante, junto com o teste de germinação, resultados confiáveis para fins de semeadura da espécie em estudo.

\section{CONCLUSÕES}

A escarificação química com ácido sulfúrico durante 5 min reduz a dormência e promove incrementos na qualidade fisiológica das sementes de $H$. sabdariffa $\mathrm{L}$.

\section{AGRADECIMENTOS}

A Universidade Estadual de Montes Claros - UNIMONTES, pelo suporte técnico, e à Fundação de Amparo à Pesquisa do Estado de Minas Gerais (FAPEMIG), pelo apoio financeiro.

\section{REFERÊNCIAS BIBLIOGRÁFICAS}

ALVES, E. U.; BRUNO, R. L. A.; OLIVEIRA, A. P.; ALVES, A. U.; ALVES, A. U. 2006. Ácido sulfúrico para superação da dormência de unidade de dispersão de juazeiro (Zizyphus joazeiro Mart.). Revista Árvore, v.30, n.2, p.187-195.

AMARO, H. T. R.; ASSIS, M. de O.; DAVID, A. M. S. de S.; SILVEIRA, J. R.; SILVA NETA, I. C.; MOTA, W. F. da. 2012. Superação de dormência em sementes de manjericão (Ocimum basilicum L.). Revista Brasileira de Plantas Medicinais, v.14, p.218-223.

ARANHO, A. S.; PAIVA, A. V. de. 2012. Superação de dormência tegumentar em sementes de Senna silvestris (Vell.) H. S. Irwin \& Barneby. Revista Biotemas, v.25, n.2, p.25-31.

BRASIL. 2010. Ministério da Agricultura, Pecuária e Abastecimento. Manual de hortaliças não-convencionais. Brasília: Mapa/ACS, 92p.

BRASIL. 2009. Ministério da Agricultura, Pecuária e Abastecimento. Regras para análise de sementes. Brasília: SNAD/DNDV/CLAV, 365p.

BRITO, A. C.; PEREIRA, D. A.; AMARAL, C. L. F. 2006. Influência da temperatura na germinação de Ocimum canum SIMS. Caatinga, v.19, n.4, p.397-401.

CASTRO, N. E. A. de; PINTO, J. E. B. P.; CARDOSO, M. G.; MORAIS, A. R. de; BERTOLUCCI, S. K. V.; SILVA, F. G. da; DELÚ FILHO, N. 2004. Planting time for maximization of yield of vinegar plant calyx (Hibiscus sabdariffa L.). Revista de Ciência e Agrotecnologia, v.28, p.542-551.

COIMBRA, R. A.; TOMAZ, C. A; MARTINS, C. C.; NAKAGAWA, J. 2007. Teste de germinação com acondicionamento dos rolos de papel em sacos plásticos. Revista Brasileira de Sementes, v.29, n.1, p.92-97.

DUTRA, A. S.; MEDEIROS-FILHO, S.; TEOFILO, E. M.; DINIZ, F. O. 2007. Germinação de sementes de Senna siamea (Lam.) H.S Irwin E Barneby Caesalpinoideae. Revista Brasileira de Sementes, v.29, n.1, p.160-164.

FERREIRA， D. F. 2008. SISVAR: Um programa para análises e ensino de estatística. Revista Científica Symposium, v.6, n.2, p.36-41.

GUIMARÃES，R. M.; OLIVEIRA，J. A.; VIEIRA, A. R. 2006. Aspectos fisiológicos de sementes. Informe Agropecuário, v.27, n.232, p.40-50.

KERMODE, A. R. 1997. Approaches to elucidate the basis of desiccationtolerance in seeds. Seed Science Research, v.7, p.75-95.

MAGUIRE, J. D. 1962. Speed of germination - aid in selection and evaluation for seedling emergence and vigor. Crop Science, v.2, p.176-177. 
MARTINS, C. C.; NAKAGAWA, J. 2008. Germinação de sementes de Stryphnodendron adstringens (Mart.) Coville de diferentes origens submetidas a tratamentos para superação de dormência. Revista Árvore, v.32, n.6.

MARTINS, C. A. da S.; LOPES, J. C.; MACÊDO, C. M. P. de. 2011. Tratamentos pré-germinativos em sementes de quiabo em diferentes estádios de maturação do fruto. Semina: Ciências Agrárias, v.32, p.1759-1770.

MELO, A. M. T. de. 2007. Hortaliças subutilizadas e sua importância no contexto da agricultura familiar. Horticultura Brasileira, v.25, n.1.. CD-ROM-palestras.

OLIVEIRA, L. M. de; BRUNO, R. L. A.; ALVES, E. U.; SOUSA, M. M.; ANDRADE, A.P. de. 2012. Tratamentos pré-germinativos em sementes de Samanea tubulosa Bentham - (Leguminoseae- Mimosoideae). Revista Árvore, v.36, n.3, p.433-440.

OLIVEIRA, L. M.; DAVIDE, A. C.; CARVALHO, M. L. M. 2003. Avaliação de métodos para quebra da dormência e para a desinfestação de sementes de canafístula (Peltophorum dubium (Sprengel) Taubert). Revista Árvore, v.27, n.5, p.597-603.

PEREIRA, T. S. 1992. Germinação de sementes de Bauhinia forficata Link. (Leguminosae Caesalpinoideae). Revista Brasileira de Sementes, v.14, n.1, p.77-82.

SANTARÉM, E. R.; AQUILA, M. E. A. 1995. Influência de métodos de superação de dormência e do armazenamento na germinação de sementes de Senna macranthera (Colladon) Irwin \& Barneby (Leguminosae). Revista Brasileira de Sementes, v.17, n.2, p.205-209.

SCALON, S. P. Q.; VIEIRA, M. C.; LIMA, A. A.; SOUZA, C. M.; MUSSURY, R. M. 2008. Tratamentos pré-germinativos e temperaturas de incubação na germinação de cipó-de-São-João [Pyrostegia venusta (Ker Gawl.) Miers] - Bignoniaceae. Revista Brasileira de Plantas Medicinais, v.10, n.4, p.37-42. SILVA, A. I. S. S.; CORTE, V. B.; PEREIRA, M. D.; CUZZUOL, G. R. F.; LEITE, I. T. A. 2009. Efeito da temperatura e de tratamentos prégerminativos na germinação de sementes de Adenanthera pavonina L. Semina: Ciências Agrárias, v.30, n.4, p.815-824.

Recebido em: 20/8/2013 Aceito para publicação em: 30/1/2014 